\title{
Office Ergonomics Assessment dengan Menggunakan MIRTH Office
}

\author{
Wahyu Fitrianda Mufti ${ }^{1}$, Demi Ramadian ${ }^{2}$, Suci Oktri Viarani $M^{1}$ \\ ${ }^{1}$ Program Studi Manajemen Logistik Industri Agro, Politeknik ATI Padang, Jl. Bungo Pasang-Tabing, Padang 25171 Indonesia \\ ${ }^{2}$ Program Studi Teknik Industri Agro, Politeknik ATI Padang, Jl. Bungo Pasang-Tabing, Padang 25171 Indonesia
}

\section{ARTICLE INFORMATION}

Received: December 15, 2020

Revised: December 28, 2020

Available online: December 31, 2020

\section{KEYWORDS}

Ergonomics, MIRTH office

\section{CORRESPONDENCE}

Name: Wahyu Fitrianda Mufti

E-mail: wahyufitrianda@poltekatipdg.ac.id

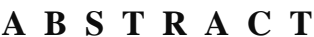

\begin{abstract}
The computerized system is closely related to today's office works. Computer works with high intensity of repetition and awkward posture can cause harm or risk. This can cause discomfort in several areas of the body. Therefore, an office ergonomics assessment that focuses on humans as the most important component is needed to determine the impact and causes of the discomfort problem. In this study, MIRTH Office is used as the assessment tools. The questionnaire consists of two parts, namely general information and conformity assessment. The data processing stage in this study consisted of problem identification and problem grouping. The results showed that most of the respondents experienced pain in the neck, shoulders, elbows, wrists and lower back. These results indicate the need of ergonomics intervention as early as possible to prevent the risk of musculoskeletal disorders.
\end{abstract}

\section{PENDAHULUAN}

Dalam dunia kerja modern, sebagian besar pekerjaan diselesaikan menggunakan sistem komputerisasi. Sistem komputerisasi sangat erat kaitannya dengan sistem kerja kantor yang tidak lepas dari elemen manusia didalamnya. Saat ini, peran manusia masih sangat dominan dalam menyelesaikan pekerjaan-pekerjaan kantor. Dengan dibantu sistem komputer, pekerjaan yang dilakukan manusia dapat diselesaikan dengan cepat dan efisien.

Bekerja didepan komputer, saat dilihat secara keseluruhan, hampir seperti tidak memiliki pengorbanan yang besar dalam aktivitas [2]. Padahal pekerjaan di kantor juga dapat membawa dampak yang tidak baik bagi keselamatan \& kesehatan pegawai [1]. Mengamati dan mempelajari pekerja kantoran di lingkungan kerja bukan merupakan hal baru. Pada awal 1700-an Bernardino Ramazzini mencatat bahwa pekerja yang duduk diam, membungkuk, memandangi pekerjaan mereka, sering berbahu bulat dan menderita mati rasa di kaki, ketimpangan dan linu panggul [3].

Bahaya dan risiko yang dapat muncul akibat pekerjaan ini dikarenakan pegawai mengerjakan pekerjaan yang berulang-ulang dengan intensitas yang tinggi dengan postur yang sama atau pada postur yang tidak normal (awkward posture), sehingga dapat menimbulkan ketidaknyamanan dalam beberapa area tubuh [4]. Oleh sebab itu office ergonomics (ergonomi kantor) yang berfokus pada manusia sebagai komponen terpenting dibutuhkan untuk mengetahui dampak dan penyebab dari permasalahan kesehatan pegawai kantor.

Ergonomi adalah keilmuan yang mempelajari interaksi antara manusia dan mesin, serta faktor yang mempengaruhi interaksi tersebut [6]. Ergonomi memiliki peran penting dalam peningkatan produktivitas dan profit suatu organisasi. Ergonomi kantor (office ergonomics) dapat diartikan sebagai aturan mengenai hubungan atau interaksi antara manusia dengan peralatan kantor saat melakukan pekerjaan di kantor [4].

Penerapan dari solusi office ergonomics akan memberikan keuntungan bagi dua pihak, yaitu pegawai dan perusahaan. Bagi pihak pegawai, kondisi area kerja menjadi aman, nyaman dan sehat sehingga mereka dapat bekerja dengan lebih baik dan mempengaruhi efisiensi dan efektivitas kerja. Bagi perusahaan, keuntungan yang diperoleh adalah produktivitas 
pegawai yang meningkat yang berdampak pada keuntungan keuangan perusahaan dan mengurangi biaya-biaya kesehatan pegawai [6]. Selain itu, intervensi ergonomi yang baik dapat mengurangi tekanan dan kelelahan fisik pada pegawai saat bekerja, serta meningkatkan moral dan motivasi pegawai, yang tentunya akan berimbas pada produktivitas kerja [5].

Kampus X merupakan salah satu kampus vokasi yang kegiatannya saat ini tidak hanya melaksanakan program belajar-mengajar di ruang kelas, tetapi juga terdapat kegiatan-kegiatan yang bersifat administratif yang dilaksanakan di ruang kantor. Sejauh ini, di kampus vokasi $\mathrm{X}$ belum pernah diadakan survei mengenai kondisi lingkungan kerja dan pertimbangan aspek kesehatan bagi pegawai yang melakukan kegiatan administratif.

Berdasarkan hal tersebut, penelitian ini dilakukan dengan tujuan melakukan evaluasi kondisi lingkungan kerja dengan konsep office ergonomic assessment. Penilaian yang dilakukan pada penelitian ini terdiri dari pengelolaan tata ruang kerja, kebisingan dan pendangan, akses permukaan kerja, pencahayaan, kursi, sandaran kaki, fitur meja, posisi dan ukuran layar, keyboard dan mouse, document holder dan istirahat. Diharapkan dengan adanya penilaian terhadap sistem kerja saat ini, dapat dirancang tindakan-tindakan yang dapat meningkatkan performansi pegawai.

\section{METODOLOGI}

Penelitian yang dilakukan dibagi menjadi lima tahapan, dimulai dari studi literatur, perancangan office ergonomic assessment, pengumpulan data, pengolahan, serta rekomendasi solusi permasalahan.

\section{Studi Literatur}

Studi literatur merupakan studi pendahuluan yang diperlukan untuk mencari acuan penelitian, yang diperoleh dari jurnal-jurnal penelitian maupun textbook. Pengamatan awal diperlukan untuk mengetahui aktivitas-aktivitas yang dilakukan serta kondisi di lapangan. Dari hasil studi pendahuluan, ditetapkan rumusan masalah dan tujuan yang ingin dicapai dari penelitian yang dilakukan.

\section{Metode Office Ergonomics Assessment}

Metode Office Ergonomic Assessment yang akan digunakan pada penelitian ini adalah MIRTH Office Checklist y [8]. Dalam metode ini setiap sumber-sumber yang memberikan resiko bahaya di kantor akan dikelompokkan, sehingga memudahkan dalam mengidentifikasi faktor risiko dalam perancangan solusi perbaikan [1]. Kuesioner yang dikembangkan terdiri dari dua bagian yaitu bagian informasi umum dan bagian penilaian stasiun kerja.

Validasi kuesioner yang akan digunakan adalah expert judgement dan pihak kampus. Hal ini diperlukan untuk menyesuaikan kondisi stasiun kerja yang ada dengan item pertanyaan.

\section{Pengumpulan Data}

Pengambilan data dilakukan dengan menyebarkan kuesioner online kepada para pegawai/karyawan yang tersebar di beberapa unit di Kampus Vokasi X. Metode pemilihan sample responden yang digunakan pada penelitian ini adalah random sampling method. Kuesioner disebar kepada 50 orang responden melalui media sosial, dan yang mengisi hanya 46 orang (response rate 92\%). Kuesioner yang disebar merupakan kuesioner bagian informasi umum, sedangkan bagian penilaian stasiun kerja dilakukan dengan pengamatan dan pengambilan data langsung.

\section{Pengolahan data}

Tahap pengolahan data pada penelitian ini terdiri dari identifikasi masalah dan pengelompokkan permasalahan. Identifikasi permasalahan dapat dilakukan dengan membandingkan jawaban yang telah diisi responden dengan dasar teori. Jawaban yang tidak sesuai mengindikasikan adanya permasalahan dalam faktor tersebut. Setiap pertanyaan yang diidentifikasi sebagai masalah akan dikelompokkan kembali, untuk memfokuskan perancangan alternatif solusi perbaikan.

\section{HASIL DAN PEMBAHASAN}

Berdasarkan pengumpulan dan pengolahan data yang dilakukan, diperoleh data tentang informasi umum responden, identifikasi permasalah dan pengelompokkan masalah.

\section{Informasi Umum Responden}

Informasi umum yang dikumpulkan dari responden antara lain jenis kelamin, umur, lama bekerja, durasi kerja di depan komputer, penggunaan mouse dan lain sebagainya. Hasil pengumpulan data tentang informasi umum responden dapat dilihat pada Tabel 1.

Berdasarkan data informasi umum responden yang terdapat pada Tabel 1, sebagian besar responden berada dalam usia produktif (25-35 tahun). Dan masih terdapat responden yang bekerja di depan komputer lebih dari jam kerja normal (lebih dari 8 jam dalam sehari). Lama waktu kerja dengan komputer juga menunjukkan ratarata waktu yang dihabiskan pegawai dalam posisi duduk. 
Tabel 1. Informasi Umum Responden

\begin{tabular}{|c|c|c|}
\hline No & Keterangan & Persentase \\
\hline \multirow{3}{*}{1} & Jenis Kelamin & \\
\hline & Pria & $37 \%$ \\
\hline & Wanita & $63 \%$ \\
\hline \multirow{5}{*}{2} & Umur & \\
\hline & $<25$ tahun & $0 \%$ \\
\hline & 25 - 35 tahun & $59 \%$ \\
\hline & 35 - 45 tahun & $30 \%$ \\
\hline & $>45$ tahun & $11 \%$ \\
\hline \multirow{5}{*}{3} & Lama bekerja & \\
\hline & $<1$ tahun & $13 \%$ \\
\hline & $1-3$ tahun & $26 \%$ \\
\hline & $3-5$ tahun & $13 \%$ \\
\hline & $>5$ tahun & $48 \%$ \\
\hline \multirow{4}{*}{4} & Durasi kerja dalam 1 hari & \\
\hline & $<4$ jam & $0 \%$ \\
\hline & $4-8$ jam & $17 \%$ \\
\hline & $>8$ jam & $83 \%$ \\
\hline \multirow{4}{*}{5} & $\begin{array}{l}\text { Durasi kerja menggunakan } \\
\text { komputer }\end{array}$ & \\
\hline & $<4$ jam & $13 \%$ \\
\hline & $4-8$ jam & $83 \%$ \\
\hline & $>8$ jam & $4 \%$ \\
\hline \multirow{5}{*}{6} & $\begin{array}{l}\text { Penggunaan mouse saat } \\
\text { bekerja dengan komputer }\end{array}$ & \\
\hline & Tidak sama sekali & $20 \%$ \\
\hline & Jarang & $15 \%$ \\
\hline & Agak sering & $30 \%$ \\
\hline & Selalu & $35 \%$ \\
\hline \multirow{3}{*}{7} & Menggunakan kacamata & \\
\hline & $\mathrm{Ya}$ & $61 \%$ \\
\hline & Tidak & $39 \%$ \\
\hline \multirow{3}{*}{8} & Mengalami gangguan mata & \\
\hline & $\mathrm{Ya}$ & $70 \%$ \\
\hline & Tidak & $30 \%$ \\
\hline \multirow{5}{*}{9} & Mengalami sakit kepala & \\
\hline & Tidak sama sekali & $7 \%$ \\
\hline & Jarang & $52 \%$ \\
\hline & Agak sering & $41 \%$ \\
\hline & Selalu & $0 \%$ \\
\hline \multirow{7}{*}{10} & Rasa nyeri yang dirasakan & \\
\hline & Di leher & $43.5 \%$ \\
\hline & Di bahu & $69.6 \%$ \\
\hline & Di siku dan lengan bawah & $17.4 \%$ \\
\hline & Di pergelangan tangan dan jari & $30.4 \%$ \\
\hline & Di punggung bagian bawah & $52.5 \%$ \\
\hline & Di bagian kaki & $8.7 \%$ \\
\hline
\end{tabular}

Dari tabel di atas juga diketahui sebagian besar responden mengalami gangguan mata dan mengalami sakit kepala. Akibat dari penggunaan komputer yang terlalu lama. Hal ini juga menyebabkan rasa nyeri yang banyak dirasakan di bagian bahu, leher dan punggung 74 Mufti et al bagian bawah. Dua kondisi keluhan ini mengindikasikan perlunya perbaikan stasiun kerja bagi karyawan.

\section{Identifikasi Permasalahan}

Langkah selanjutnya yaitu melakukan identifikasi permasalahan dengan cara membandingkan jawaban yang diberikan responden pada saat pengamatan/pengambilan data dengan kesesuaian standar yang ada. Stasiun kerja dengan kondisi yang belum mencapai syarat, kondisi minimum dan posisi kerja pegawai belum baik, mengindikasikan adanya permasalahan.

Permasalahan-permasalahan yang diidentifikasi adalah permasalahan yang terdapat didalam kuesioner pengambilan data. Contoh dari identifikasi permasalahan dapat dilihat pada Tabel 2.

Tabel 2. Contoh Identifikasi Permasalahan

\begin{tabular}{|c|c|c|c|}
\hline No & Hal-Hal yang Diamati & \multicolumn{2}{|c|}{$\begin{array}{l}\text { Kesesuaian } \\
\text { Kondisi }\end{array}$} \\
\hline 1 & Tata Letak Ruang Kerja & Ya & Tidak \\
\hline 1.1 & $\begin{array}{l}\text { Apakah susunan meja dan } \\
\text { kursi kerja dapat dirubah } \\
\text { dengan mudah? }\end{array}$ & $\sqrt{ }$ & \\
\hline 1.2 & $\begin{array}{l}\text { Apakah alat - alat kerja } \\
\text { dapat dijangkau dengan } \\
\text { mudah? }\end{array}$ & $\sqrt{ }$ & \\
\hline 1.3 & $\begin{array}{l}\text { Apakah disekeliling kursi } \\
\text { terdapat ruang kosong } \\
\text { minimal } 2 \mathrm{~m}^{2} \text { ? }\end{array}$ & & \\
\hline 1.4 & $\begin{array}{l}\text { Apakah jarak meja dengan } \\
\text { penghalang terdekat lebih } \\
\text { dari } 115 \mathrm{~cm} \text { ? }\end{array}$ & & \\
\hline 1.5 & $\begin{array}{l}\text { Apakah tinggi loteng sama } \\
\text { dengan } 2,5 \mathrm{~m} ?\end{array}$ & $\sqrt{ }$ & \\
\hline
\end{tabular}

Pertanyaan-pertanyaan yang di jawab Tidak oleh responden mengindikasikan adanya permasalahan. Pada penelitian ini, permasalahan yang akan direkapitulasi dan diberikan solusi alternatif adalah permasalahan dengan nilai persentase $\mathrm{di}$ atas $50 \%$. Adapun rekapitulasi darri identifikasi permasalahan dapat dilihat pada Gambar 1 di bawah ini.

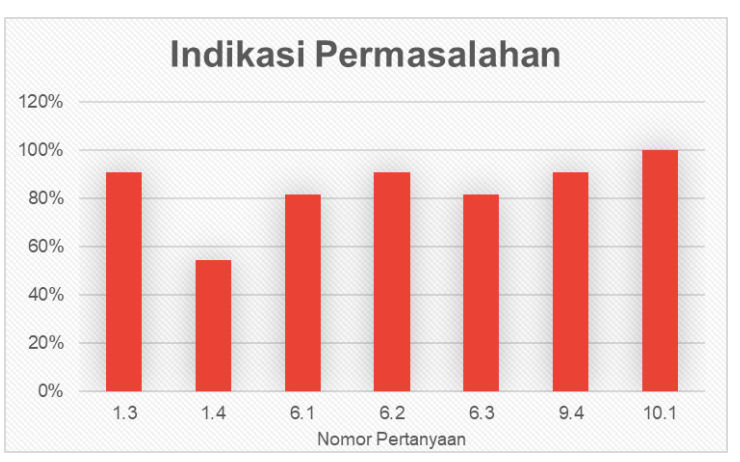

Gambar 1. Histogram Indikasi Permasalahan 


\section{Pengelompokkan Masalah}

Langkah selanjutnya setelah dilakukan identifikasi permasalahan adalah pengelompokkan masalah yang bertujuan untuk mempermudah dalam merancang alternatif solusi. Pengelompokkan masalah dilakukan berdasarkan keluhan yang dialami responden. Adapun kelompok permasalahan yang terbentuk adalah:

a. Permasalahan terkait Tata Letak Ruang Kerja

b. Permasalahan terkait Fasilitas Kerja

\section{Pembahasan}

Pembahasan dalam penelitian ini dibagi menjadi dua bagian, yaitu pembahasan mengenai pengelompokkan masalah dan pembahasan alternatif solusi dari permasalahan tersebut.

\section{Pembahasan Mengenai Kelompok Permasalahan}

Pengelompokkan masalah pada penelitian ini dilakukan berdasarkan keluhan yang dialami oleh responden. Adapun permasalahan yang dihadapi dibagi kedalam dua kelompok, yaitu:

\section{a. Permasalahan terkait Tata Letak Ruang Kerja}

Permasalahan yang berkaitan dengan tata letak ruang kerja pada penelitian ini terdiri dari peletakan furnitur dan alat-alat kerja dan keleluasaan bergerak. Dari kedua permasalahan tersebut yang memiliki frekuensi tertinggi adalah keleluasaan bergerak pegawai. Keleluasan bergerak disini terkait dengan ruang kosong yang tersedia disekeliling kursi dan jarak antara meja kerja dengan penghalang terdekat kurang dari $115 \mathrm{~cm}$. Gambar 2 di bawah ini menunjukkan tata letak ruang bagian administratif.

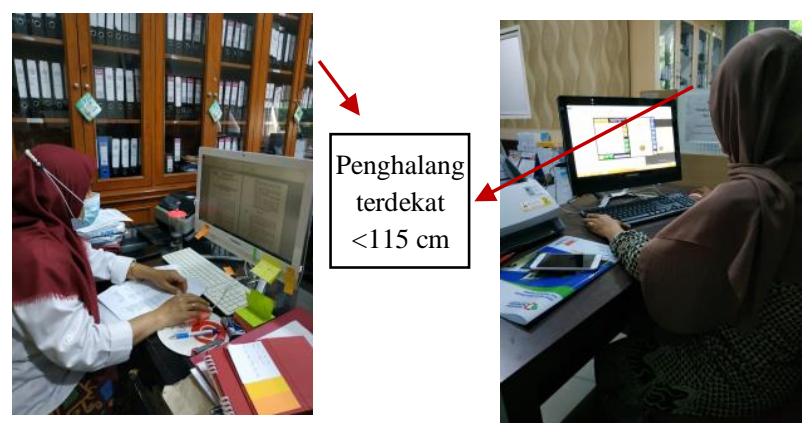

Gambar 2. Jarak meja dengan penghalang sangat dekat

Secara ergonomis, para pegawai hendaklah diberi ruang agar mereka dapat leluasa bergerak, seperti saat mereka ingin untuk istirahat atau sekedar menggerakkan badan. Hal ini dibutuhkan oleh pegawai yang bekerja di depan komputer yang melebihi jam kerja normal. Dari hasil pengamatan didapatkan bahwa sebagian besar responden yang tidak dapat dengan leluasa bergerak mengalami keluhan di bagian kaki karena terlalu lama duduk, di bagian siku dan lengan bawah karena tangan tidak mendapatkan ruang yang pas.

\section{b. Permasalahan terkait Fasilitas Kerja}

Masalah yang terkait dengan fasilitas kerja adalah sandaran kaki, keyboard dan mouse dan document holder. Kebanyakan meja kerja yang digunakan saat ini tidak memiliki sandaran kaki, kecuali beberapa pegawai yang masih menggunakan fasiitas meja kerja yang lama. Namun sandaran kaki yang terdapat pada meja yang lama juga digunakan untuk menempatkan dokumendokumen, sehingga sandaran kaki yang ada tidak dapat digunakan dengan maksimal. Gambar 3 menunjukkan tidak terdapatnya sandaran kaki di meja kerja pegawai.


Gambar 3. Sandaran kaki tidak tersedia

Permasalahan selanjutnya berkaitan dengan keyboard dan mouse. Beberapa pegawai lebih memilih untuk menggunakan laptop dari pada menggunakan unit PC yang tersedia. Saat menggunakan laptop maupun unit PC, umumnya pegawai tidak menggunakan penyangga tambahan sehingga peletakkan keyboard tetap pada posisi mendatar. Penyangga keyboard berfungsi untuk mengurangi contact stress pada pergelangan dan jari tangan. Posisi peletakkan keybooard dan mouse dapat dilihat pada Gambar 4 di bawah ini.

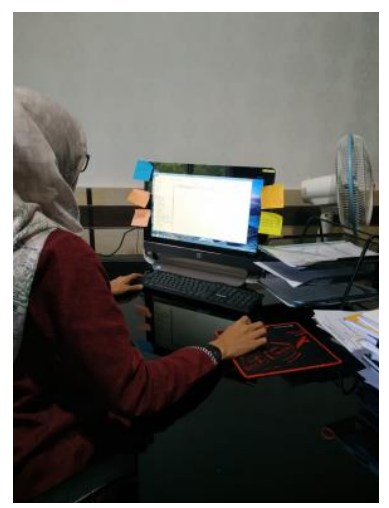

Gambar 4. Peletakkan keyboard dan mouse

Selain sandaran kaki dan keyboard dan mouse, terdapat satu masalah lagi terkait fasilitas kerja yaitu document holder. Lazimnya, dengan menggunakan document holder maka pegawai saat melakukan pengetikan tidak perlu menunduk untuk membaca dokumen. Document 
holder ini sangat dibutuhkan bagi pegawai yang banyak melakukan kegiatan administrasi seperti bagian akademik dan umum. Berkaitan dengan masalah ini, sebagian responden mengalami keluhan musculoskeletal di bagian leher. Hal ini dipengaruhi oleh sikap kerja saat membaca dokumen yaitu menunduk atau memiringkan kepala.

\section{Pembahasan Mengenai Alternatif Solusi}

Alternatif solusi yang diberikan disesuaikan dengan kelompok permasalahan yang ada. Hal ini bertujuan untuk memfokuskan pemecahan masalah.

\section{a. Alternatif Solusi Tata Letak Ruang Kerja}

Permasalahan utama terkait tata letak ruang kerja adalah ketidaktersediaan ruangan untuk keleluasaan bergerak. Alternatif solusi yang dapat diberikan adalah dengan mengatur ulang penyusunan furniture-furniture yang terdapat di dalam ruangan, kemudian memperkirakan ruang kosong yang tersedia disekeliling kursi. Juga mempertimbangkan penempatan penghalang antar meja, agar pegawai dapat bergerak dengan leluasa tanpa adanya gangguan dari penghalang.

\section{b. Alternatif Solusi Fasilitas Kerja}

Salah satu permasalahan utama terkait fasilitas kerja adalah ketidaktersediaan sandaran kaki yang terdapat pada meja kerja. Untuk mengatasi permasalahan ini, solusi yang dapat diberikan adalah dengan menambahkan sandaran kaki yang di bawah meja kerja dengan ukuran kedalaman sesuai dengan office ergonomics principle. Sandaran kaki merupakan salah satu faktor krusial karena berkaitan dengan postur tubuh selama bekerja. Hal ini berguna untuk meminimalisir risiko keluhan pada bagian kaki (contoh: kaki bengkak). Gambar sandaran kaki dapat dilihat pada Gambar 5.

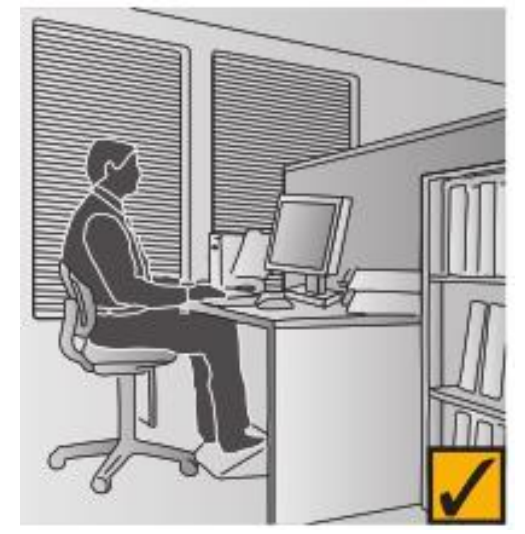

Gambar 5. Penggunaan sandaran Kaki [9]

Selain itu ketidaktersediaan document holder, sehingga pegawai perlu menunduk saat membaca dokumen dan menimbulkan keluhan pada bagian leher. Alternatif solusi yang dapat diberikan adalah dengan menambahan documen holder pada bagian yang banyak berkaitan dengan kegiatan administrasi dan input data. Gambar document holder yang dimaksud dapat dilihat pada Gambar 6.

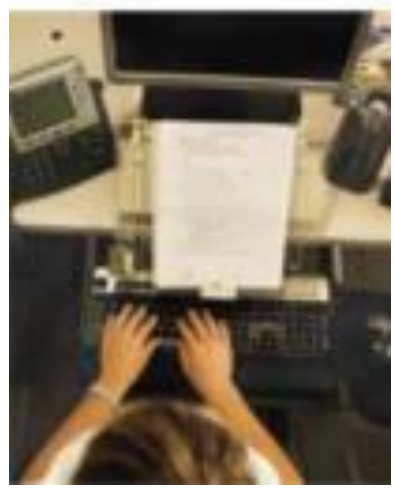

Gambar 6. Penggunaan document holder [4]

Dalam mengatasi permasalahan yang berkaitan dengan peletakan keyboard dan mouse, alternatif solusi yang dapat diberikan adalah dengan menyediakan penyangga untuk peletakan keyboard agar posisi pergelangan tangan berada dalam posisi netral.

\section{KESIMPULAN}

1. Hasil dari penelitian yang telah dilakukan menunjukkan terdapat dua kelompok permasalahan yang berkaitan dengan office ergonomics, antara lain permasalahan terkait tata letak ruang kerja dan fasilitas kerja.

2. Alternatif solusi yang diberikan didasarkan kepada kelompok permasalahan yang ada.

3. Hasil dari survei yang dilakukan menunjukkan bahwa sebagian besar responden mengalami rasa nyeri di bagian bahu dan punggung bagian bawah. Hal ini merupakan latar belakang perlunya penerapan ergonomi dilakukan sedini mungkin.

\section{DAFTAR PUSTAKA}

[1] Aisha, A. N. "Office Ergonomics Assessment Pada. Office Ergonomics Assessment Pada Kantor Bank X”. Jurnal Rekayasa Sistem \& Industri, Volume 1, Nomor 1, 2014, Hal 68-74.

[2] D. Boseen. "Improved Workplace Performance and Productivity Through Movement: The Emerging Role of Adjustability". Atlas Ergonomics, 2007.

[3] Kroemer, A. D., \& Kroemer, K. H. E. Office ergonomics: Ease and efficiency at work, Second edition. London, New York: CRC Press. 2016

[4] Occupational Helath Clink for Ontario Workers Inc. Office Ergonomics Handbook Fifth Edition. Ontario, Canada: n.p., 2008. 
[5] Texas Department of Insurance. "Office Ergonomics”. 2009. http://www.tdi.texas.gov/pubs/.../wpofficeergo.pdf

[6] R.S. Bridger. Introduction to Ergonomics $2^{\text {nd }}$ Edition. London, UK: Routledge. 2003.

[7] K. Taylor, dan N. Green. The Productivity Benefits of Office Ergonomics Interventions: A Review of the Current Literature. Wellnomics White Paper. 2008.

[8] T. Gallwey dan L. O'Sullivan. MIRTH Office Checklist. University of Limerick Ergonomics Research Centre. 2010.

[9] Work Safe Victoria, A handbook for workplaces: Officewise - A guide to health \& safety in the office Edition No.5, Melbourne, Australia: n.p., 2006. 